outlets for demographers, the incentive to specialize being correspondingly small. Perhaps, however, there should be less specialization. In those vast areas of the world where population growth presses so menacingly upon under-developed economies, pure demographers are less in demand than those with a wider and multidisciplined approach, an under standing of the subtle inter-relationships between demographic, geographical, ecological, social and economic factors. Just how wide the field of knowledge must be is excellently illustrated in the closing chapters of this symposium. Everywhere knowledge is incomplete. Information concerning land and other resources, the effect of locational factors, genetic changes and biological influences, cultural forces, and the manner of community expansion and reorganization-all this now concerns the population student.

If any part of the book is to be criticized, it is the form and content of the middle chapters. This is not a question of factual or expository deficiency, for authorship is of a very high standard. One gets the impression of a little too much erudition, particularly too much factual content, and not enough concen. tration upon methods of measurement. The chapter on population distribution criticizes the descriptive and one-sided character of contemporary studies, but appears to favour methods of multiple regression analysis which succeed only to the extent that they are descriptive, and are in disrepute because they have built-in hazards of interpretation. It ignores the volumetric approach of the geographer. The fertility chapter affords little space to the index problem in measurement and concentrates more on the subject of fertility regulation ; on the other hand, the chapter on population replacement is largely confined to methods of arithmetic with barely enough interpretative caution. But it must be admitted that it is always difficult to decide how much space to allot to explaining how to measure and how much to discussing the essential character of the events that are being measured. The book is claimed to be an encyclopredic summary. It is a difficult feat of editorship to prevent this from being a contradiction in terms and the editors are to be congratulated on a very high measure of success. This is more than a reference book; it will attract sustained study.

B. BENJAMIN

\section{STERIC EFFECTS IN ORGANIC MOLECULES}

\section{Steric Effects in Conjugated Systems}

Proceedings of a Symposium held at the University, Hull, 15-17 July, 1958, by the Chemical Society. Edited by Dr. G. W. Gray. Pp. viii + 181. (London: Butterworths Scientific Publications; New York : Academic Press, Inc., 1958.) 30s.

$\mathrm{T}$ HIS relatively inexpensive book is a useful addition to the small number of books concerned with steric effects in organic molecules. It contains the fifteen original papers, together with 44 pages of ensuing discussion, which were read at the symposium held in Hull during July 15-17, 1958.

A lucid historical survey by E. E. Turner was followed by seven papers in which the relationship between the light absorption and the conformation of conjugated systems was discussed. The theoretical treatments of C. A. Coulson and of W. F. Forbes were accompanied by papers by G. H. Beaven, C. C. Barker, and by E. S. Waight and R. L. Erskine, incorporating detailed measurements of the spectra of numerous alkyl diphenyls, di- and tri-phenylmethane dyes, and conjugated carbonyl compounds, respectively. Certain spectral data were related to rates of reaction and the $p K_{a}$ by B. M. Wepster, though the author pointed out that this approach is not universally applicable.

Attempts to evaluate steric and electronic effects with the aid of kinetic data were described in four papers. The rates of nucleophilic aromatic substitution, of the solvolysis of aralkyl halides, of the acidcatalysed $\mathrm{H}-\mathrm{D}$ exchange in aromatic hydrocarbons, and of a variety of reactions involving ortho-substituted compounds were discussed, respectively, by N. B. Chapman, H. C. Brown, G. Dallinga et al., and A. C. Farthing and B. Nam.

The remaining papers illustrated the application of other physical methods. A paper by E. A. Johnson on the gas-liquid chromatography of alkyldiphenyls provided an interesting complement to that by Beaven. Contributions by J. W. Smith and by G. W. Gray described dipole moment measurements and observations on mesomorphism, respectively.

In summary, this collection of original papers embodying review material and some discussion provides a valuable survey of contemporary studies concerning the conformations of conjugated molecules.

\section{G. EgLINTON}

\section{COLORIMETRY}

\section{Colorimetric Methods of Analysis, including Photo-} metric Methods

Vol. 2A. By Dr. Foster Dee Snell and Dr. Cornelia T. Snell, assisted by Dr. Chester Arthur Snell. Pp. $x+793$. (New York: D. Van Nostrand Company, Ine.; London: D. Van Nostrand Company, Ltd., 1959.) 112s. $6 d$.

$7 \mathrm{HE}$ volume under review supplements the data given in the third edition (1948-54) of Volume 2, and includes all the important publications which have appeared prior to January 1956. In dealing with such a vast compilation, now five volumes, the authors cannot from their personal experience recommend any particular method, and the question arises as to whether treatises such as this have a universally useful function. The answer appears to be that this treatise has been compiled by a team of experienced abstractors who can consult their own analytical department, and who are thus well able to judge whether a method merits recording or not.

The scheme adopted throughout the volume is both logical and helpful to the reader. Each chapter is headed by a brief deseription of now and useful additions to the methods described in the previous edition of Volume 2. Where the method is the result of collaborative study by a number of laboratories it is frequently given almost in full. Thus the reader can proceed with such a method in confidence, knowing that it has been tested in a number of independent laboratories, and has justified its publication by a representative body of experts. While this results in recording methods which have proved sound, these methods may not be the best available even shortly after publication, since collaborative studies between widely separated laboratories are necessarily very time consuming. 